\title{
CRIANÇAS TAMBÉM SE ESTRESSAM? A INFLUÊNCIA DO ESTRESSE NO DESENVOLVIMENTO INFANTIL
}

\author{
LOS NIÑOS TAMBIÉN SE ESTRESAN? LA INFLUENCIA DEL ESTRÉS \\ EN EL DESARROLLO INFANTIL
}

\section{CHILDREN ALSO GET STRESSED? THE INFLUENCE OF STRESS IN CHILD DEVELOPMENT}

\author{
Marsiel PACÍFICO ${ }^{1}$ \\ Marcele Martins Provinciatti FACCHIN ${ }^{2}$ \\ Fabiana de Fatima Ferreira CORRÊA SANTOS ${ }^{3}$
}

RESUMO: O estresse é uma reação do organismo com componentes psicológicos, físicos e hormonais que ocorre quando surge a necessidade de uma grande adaptação a um evento ou uma situação de importância, podendo esse ser algo negativo ou positivo, causado por inúmeros fatores do nosso cotidiano. Atualmente observamos que esta patologia também atinge as crianças: rotina intensa, pais estressados, relações parentais atravessadas pelas marcas afetivas do estresse. São fatores, dentre outros, que contribuem para o surgimento deste mal na infância. Ademais são raros os estudos que compreendem as características específicas da enfermidade na criança e quais as consequências para seu desenvolvimento. Frente a este contexto, os objetivos do presente estudo são caracterizar o estresse em seu contexto social e analisar seu impacto, sobretudo na infância, identificando possibilidades para auxiliar a lidar com este problema.

PALAVRAS-CHAVE: Estresse. Infância. Modernidade. Estresse infantil.

RESUMEN: El estrés es una emisión de un organismo con componentes psicológicos, físicos y hormonales que se produce cuando surge una necesidad de una gran adaptación a un evento o una situación de importancia, que puede ser algo negativo o positivo, causado por muchos factores de nuestro cotidiano. Observamos que esta patología también se encuentra en las zonas rurales: rutina intensa, padres estresados, relaciones parentales atravessadas por marcas afetivas do estresse. São factores, dentre otros, que contribuyen para el surgimiento de este mal en la infancia. Ademais são raros en los estudios que comprenden como características específicas de la enfermidad en la niñez y en las que como consecuencia para su desarrollo. Frente a este contexto, los objetivos de este estudio se caracterizan por su contexto socioeconómico y su impacto, sobre la infancia, identificando posibilidades para ayudar a resolver este problema.

${ }^{1}$ Universidade Estadual de Ponta Grossa (UEPG), Ponta Grossa - PR - Brasil. Doutor em Educação (2013-2017) na linha de pesquisa do PPGE/UFSCAR. E-mail: marsiellp@ gmail.com

${ }^{2}$ Campos Elísios. Diretora Escolar. Especialista em Neuropsicopedagogia. E-mail: safce.artigo@gmail.com

${ }^{3}$ Campos Elísios. Professora Especialista em Neuropsicopedagogia. E-mail: safce.artigo@gmail.com 
PALABRAS-CLAVE: Estrés. Infancia. Modernidad. Estrés infantil.

ABSTRACT: Stress is a reaction of the organism with psychological, physical and hormonal components that occurs when the need for a great adaptation to an event or situation of importance arises, which can be something negative or positive, caused by many factors of our daily life. We now observe that this pathology also affects children: intense routine, stressed parents, parental relationships crossed by the affective marks of stress, are factors, among others, that contribute to the onset of this evil in childhood. In addition, there are few studies that understand the specific characteristics of the disease in children and what the consequences for their development. Against this background, the objectives of the present study are to characterize stress in its social context and to analyze its impact, especially in childhood, identifying possibilities to help deal with this problem.

KEYWORDS: Stress. Childhood. Modernity. Child stress.

\section{O contexto moderno e a proliferação dos fatores estressores}

O agravamento do estresse no século XXI envolve o atual modelo socioeconômico, caracterizado pelo excesso de atividades, má distribuição do tempo, acúmulo de raiva e sentimentos negativos, problemas de relacionamento, dificuldades em lidar com perdas, falta de descanso e lazer ou ainda descontrole em situações críticas.

O horário do serviço, a falta de emprego, a compra da casa própria, pagamento do aluguel, brigas com a família, reconciliação entre parentes, informações sobre o que acontecesse no ambiente em que vive ou, até mesmo, dos outros continentes, são aspectos constantes que influenciam nos acontecimentos do lar, uma vez que estes aspectos são considerados fatores estressantes

Cada vez mais somos levados a nos "trancar" em casa e tentar fugir dos acontecimentos "lá de fora". Mas, apesar dessa sensação de segurança, somos invadidos pelos problemas externos, quando usamos, por exemplo, os meios de comunicação (televisão, rádio, jornal, computador). De todas as maneiras somos levados a lidar com o mundo que vivemos; se não ocorre o interesse por informações, o indivíduo é classificado como "alienado", estando fora do contexto.

Neste contexto, um aspecto que vem chamando a atenção é a questão do estresse. O estresse é uma reação do organismo, com componentes psicológicos, físicos, 
mentais e hormonais. Ele ocorre quando surge a necessidade de uma grande adaptação a um evento ou uma situação de importância (LIPP, 2000).

\section{O que é o estresse? Conceito e características}

Muitas das situações que o ser humano enfrenta no seu cotidiano podem desencadear reações, a princípio úteis ao organismo, mas podem ser inadequadas segundo o contexto que se trata. Em algumas ocasiões, as consequências constituem alterações que comprometem a saúde do homem. Assim, as mudanças que se produzem perante os desafios e as ameaças da vida são úteis ou prejudiciais? A resposta a esta questão vai depender da análise de três problemas fundamentais: a adaptação a situações de extrema intensidade, duração ou incerteza; a interação entre os processos mentais, campo tradicionalmente exclusivo da psicologia, e suas interações com as moléculas que servem de mensageiros químicos do organismo; e, finalmente, a conhecida, porém incompreendida, relação entre as emoções e as afetações da saúde.

É neste contexto que se pode pensar sobre o estresse e seus impactos para a vida do ser humano. O estresse é um dos problemas de saúde que mais atinge a civilização moderna. Existe desde o início dos tempos, modelando nosso estilo de vida, administrando o tempo e determinando o ritmo que vivemos, podendo gerar o impulso necessário para desencadear qualquer ação. Por viver em uma era de grandes mudanças que acontecem cada vez mais rápido, o ser humano encontra-se mais sujeito a pressões para adaptação, convivência e competição, das quais não consegue escapar. Atingir o equilíbrio entre muito e pouco estresse tornou-se um desafio essencial da vida a partir dos anos 1990 (GONZALEZ, 2001).

O estresse não é apenas um problema das pessoas que vivem em ritmo acelerado. Os que sofrem de monotonia excessiva, tédio, frustração devido a uma pequena quantidade de desafios também ficam doentes com frequência. $O$ aborrecimento, a inveja e a perda de autoestima advindos do desemprego também são, hoje em dia, fontes comuns desta doença. Revelamos os efeitos do estresse por motivos como ambição, perfeccionismo e dedicação ao trabalho. Além disso, os efeitos do “estresse mascarado" são os mais comuns por serem difíceis de identificar (GONZALEZ, 2001).

Considerando-se esses aspectos, é importante pontuar que a palavra "estresse" tem origem na palavra inglesa "stress", que significa "pressão", "tensão" ou 
"insistência". Sendo assim, pode-se definir estresse como um conjunto de reações fisiológicas necessárias para a adaptação a novas situações. Contudo, essas reações orgânicas e psíquicas podem provocar desequilíbrio no organismo se forem exageradas em intensidade ou duração. O estresse pode ser desencadeado por estados emocionais tanto negativos quanto positivos, sendo a adaptação ao meio o objetivo final do processo.

É importante pontuar que, estresse provém da física e se estendeu para as ciências do comportamento e para a biologia. Também chamada de Síndrome Geral de Adaptação - seria, um sinal de alarme, prevenindo-nos quanto ao surgimento de uma ruptura da homeostase orgânica e do começo de uma doença. Teríamos então, a fase de alarme, seguida por um período de resistência e busca de equilíbrio e, finalmente, a fase de exaustão-colapso (ARANTES; VIEIRA, 2002).

Fez-se uma recuperação dos primeiros achados sobre o conceito, introduzido em 1956, por Selye, que segundo seu propositor, se desenvolve em três fases, a de alerta, a resistência e a exaustão. A fase de alerta é considerada a fase positiva, preparando a pessoa para enfrentar a situação, para em seguida retomar o seu equilíbrio. Caso o estressor não seja eliminado, o organismo passa para a segunda fase, a de resistência, na qual a pessoa tenta se adaptar, gastando muita energia para lidar com o fator estressante. Já na fase de exaustão há um forte desgaste do organismo, podendo surgir patologias. Em todas as fases há alguns sintomas, que variam de intensidade, como, por exemplo, sensação de desgaste físico constante, aumento da hipertensão arterial, irritabilidade excessiva, mudança extrema de apetite, tontura frequente, úlcera, cansaço excessivo, angústia, perda do senso de humor, dentre outros.

Uma quarta fase foi identificada por Lipp (1990) e chamada de quase exaustão. Segundo a autora, encontra-se entre as fases de resistência e exaustão, provocando na pessoa uma sensação forte de esgotamento, afetando a memória e aumentando a chance de descontrole emocional. É importante lembrar que nem sempre a pessoa passa pelas quatro fases e só alcançará a fase de exaustão quando o estressor for muito grave e não conseguir se adaptar à situação.

Neste contexto, então, é importante destacar que, a resposta de estresse abrange uma ampla participação do sistema endócrino e do nervoso. A união funcional desses dois sistemas de integração do ser humano tem possibilitado o surgimento do conceito de neuroendocrinologia, a ciência que abrange, entre outros aspectos, o controle neural da secreção hormonal e os efeitos dos hormônios sobre o comportamento. A interação 
do sistema nervoso e endócrino ainda não é totalmente conhecida, sobretudo o que diz respeito a como, no cérebro, as células especializadas convertem um estímulo em sinal nervoso e este, por sua vez, na liberação de hormônios. O processo inverso de como são transformados os sinais hormonais em sinais nervosos também não é compreendido, ainda, na sua totalidade (GONZALEZ, 2001).

Assim, quando sentimos o mundo cair sobre a cabeça, o cérebro nos prepara para reagir ao desastre. Ficamos prontos para tomar decisões com mais rapidez, guardar informações que podem ser decisivas e encarar desafios e perigos, ou seja, pessoas estressadas potencializam sua capacidade de superar um problema. Mas há um senão: se nos estressamos demais, os efeitos benéficos acabam revertidos. Nosso cérebro falha e muitas funções, como a memória, acabam sendo prejudicadas. É por isso que precisamos aprender a apreciar o estresse com moderação. O segredo estaria em levar uma vida saudável e buscar atividades que propiciem prazer.

O estresse, então, é o estado com o qual o corpo responde a essas exigências. Trata-se de um conjunto de reações que ocorrem em um organismo quando ele está submetido ao esforço de adaptação. Apesar das pesquisas enfatizarem a conotação negativa do estresse, devemos lembrar que certo grau de desafios no cotidiano pessoal, profissional e social pode se converter em propulsão de crescimento e desenvolvimento dos seres humanos (COSTA, et al 2005).

Além disso, o estresse é uma força positiva que possibilita a sobrevivência, pois, permite que a pessoa fique alerta para que desempenhe algumas atividades que são perigosas. Somente quando sobrecarregamos nossos recursos para lidar com o estresse ou quando não podemos ou conseguimos controlar nossas respostas a ele é que começam os efeitos negativos. Nesse caso, a literatura especializada refere-se a esta condição como distresse. Sabe-se que o distresse contribui tanto para doenças orgânicas como para doenças mentais, até mesmo os distúrbios psiquiátricos, fazendo com que cada vez mais os atendimentos na área psicossocial sejam procurados (Costa, et al 2005).

Atualmente, vive-se um tempo de grandes exigências de realizações pessoais e profissionais, além de demandas sociais das mais variadas, gerando muitas e difíceis tomadas de decisões. Frente a esta realidade, Lipp, et al (1991, p. 20) caracterizam o estresse como "um conjunto de reações que temos quando algo acontece que nos amedronta, nos irrita, excita ou nos faça extremamente felizes". Pode-se considerar que qualquer situação, boa ou ruim, que leva a uma quebra da homeostase do ser humano e 
possibilita uma adaptação, gera estresse, mas que só será prejudicial se houver uma predisposição do indivíduo para tanto. Assim sendo, a resposta ao estresse é o resultado da interação entre características da pessoa e as demandas do meio em que vive, e está relacionada aos aspectos cognitivos, comportamentais e fisiológicos (MARGIS, et al, 2003).

Além disso, Tavares (2004, p. 25) aponta que "pertencer e participar de um mundo externo além do nosso mundo interno implica conviver constantemente com uma dose de estresse. $\mathrm{O}$ estresse sob medida é um elemento vinculado ao processo de desenvolvimento". Assim, o estresse funciona tanto como uma força que pode facilitar como prejudicar o desenvolvimento, em que a energia vital dos impulsos deverá encontrar um caminho a respeito do estresse.

É necessário pontuar que existem modelos teóricos que visam explicar a questão do estresse. $\mathrm{O}$ modelo de tensões cotidianas, tanto quanto a visão precedente de eventos de vida estressantes, têm seu foco no adulto. Contudo, a maior parte das pesquisas relacionando estresse, coping e ajustamento em crianças e adolescentes tende a reproduzir esse modelo, sem considerar a especificidade dos processos de desenvolvimento que possivelmente estão implicados nos resultados (DELL'AGLIO; HUTZ, 2002).

O advento da concepção de tensões cotidianas, ao colocar em realce nas variáveis proximais, abriu perspectivas para a investigação de tais processos. Os estudos focalizando processos de desenvolvimento envolvidos na relação entre o estresse e o ajustamento têm sido guiados por uma concepção transacional e ecológica do desenvolvimento, inspirada nas elaborações de Sameroff (1975) e Bronfenbrenner (1996). De acordo com essa visão, propriedades do ambiente influenciam características do indivíduo, e estas, por sua vez, influenciam o ambiente. Em consequência, o desenvolvimento de condições saudáveis ou patológicas é visto como uma sequência de transações entre estados da pessoa e do ambiente; cada um dos quais contribui para uma organização individual do desenvolvimento através do tempo. Assim, o modelo enfatiza a natureza transacional da relação entre elementos ecológicos na vida de uma criança e o curso do seu desenvolvimento, seja em direção à saúde seja em direção à desadaptação (MARTURANO, 2008). 


\section{Crianças também se estressam?}

Sendo um momento propício ao desenvolvimento de novas competências, a transição da primeira série é também um período de imprevisibilidade e incertezas, condições que são geradoras de estresse e ansiedade para as crianças. As demandas da nova situação requerem um trabalho de adaptação típico das transições da vida, trabalho esse que envolve, segundo Elias (1989), pelo menos quatro tarefas: (a) ajustar-se às mudanças nas definições de papéis e comportamentos esperados; (b) situar-se na rede social ampliada; (c) adequar-se às normas e regras, explícitas e implícitas, do novo contexto; (d) lidar com o estresse associado à imprevisibilidade e às incertezas inerentes à situação como um todo.

Em termos de avaliação do estresse, considerando os instrumentos para a avaliação voltados para a população brasileira, tem-se a "Escala de Stress Infantil" ESI, de Lipp e Lucarelli (1998), e a "Escala de Stress do Adulto" - ESA, de Lipp. Santos e Pacanaro (2007) ressaltam que a Escala de Stress Infantil (ESI) constitui-se no principal instrumento usado por pesquisadores para avaliação do estresse infantil a partir dos seis anos. Entretanto, há necessidade de novos estudos para a avaliação de crianças mais jovens, pois Horta (2007) já identificou indicadores de estresse em crianças pré-escolares.

Inicialmente, procurou-se a instituição de educação infantil da rede pública de ensino, que prontamente permitiu a realização da pesquisa. A seguir, foram realizados contatos com escola a fim de conhecer o espaço físico, explicar os objetivos e procedimentos da pesquisa, e finalmente iniciou-se a execução do trabalho (Horta, 2007).

A programação inicial era estabelecer contato com as professoras, a fim de identificar crianças que apresentassem algum tipo de problema, seja ele de ordem física, cognitiva, emocional, comportamental, etc. Nas crianças indicadas pelas professoras seria aplicada a Escala de Stress Infantil (ESI) para que pudessem ser escolhidos os casos. Contudo, foram indicados poucos alunos, o que foi julgado como algo que deveria ser melhor avaliado, haja vista a possibilidade de as professoras não estarem percebendo os problemas de seus alunos e também a possibilidade de que muitos deles poderiam não estar expressando suas dificuldades na escola. Assim, decidiu-se por aplicar a escala em todos os alunos do pré-5 e do pré-6, o que totalizou 44 crianças a serem avaliadas. 
As entrevistas com as crianças, mães e professoras permitiram identificar as prováveis fontes de estresse advindas da família e da escola, as advindas de sentimentos, crenças e comportamentos inerentes à criança, além das estratégias de coping utilizadas. Na Escala de Fontes Estressoras na Criança foi possível identificar fontes de estresse advindas de acontecimentos significativos.

A partir das entrevistas foram encontradas prováveis fontes de estresse na rotina, na interação familiar, na interação com os colegas, na interação com a professora, nas características da escola e nos sentimentos, crenças e características da própria criança. Além disso, na Escala de Fontes Estressoras foram reveladas diversas situações, potencialmente estressoras, pelas quais a criança passou no último ano (HORTA, 2007).

Atualmente, o estresse não atinge apenas adultos envolvidos com a rotina intensa da vida moderna e preocupados com as despesas da família.

\begin{abstract}
Além de ser um problema sério, o estresse também afeta crianças e até bebês. O estresse é uma arma do corpo que surge em qualquer tipo de ambiente ou situação hostil. E isso pode acontecer com um adulto, quando a chefe briga, quando ocorrem atritos em casa, por exemplo, ou com uma criança, quando enfrenta uma discussão com um colega de classe ou mesmo leva uma bronca da professora. (CROZERA, [s.d.], p.3).
\end{abstract}

Até mesmo entre os bebês há ocorrência de estresse. É muito comum que crianças bem pequenas se apresentem estressadas por conviverem com pais estressados ou ansiosos. Isso ocorre porque o bebê é muito sensível aos pais e acaba sentindo e captando as menores alterações no ambiente. "Nesses casos, é mais difícil de perceber que a criança está sendo prejudicada, sendo os principais sintomas os psicossomáticos, ou seja, as reações físicas ao problema psicológico, como problemas digestivos ou problemas de sono." (CROZERA, [s.d.], p.3).

Recentemente foi possível detectar o aparecimento de estresse em crianças a partir dos seis anos de idade em contexto brasileiro, por meio dos estudos de Lipp (2000). A autora refere-se ao fato de que o estresse infantil é pouquíssimo conhecido, sendo difícil encontrar pesquisas, tanto no Brasil quanto em outros países. As crianças estão continuamente expostas a uma estimulação excessiva, resultando em apatia da psique. Slee, Murray-Harvey e Ward (1996) identificaram eventos estressantes em um estudo com crianças de cinco anos de idade devido a: hospitalização dos pais; separação dos pais; exigências disciplinares; hospitalização da criança; sequestro de membro da 
família; mudança de residência; ausência dos pais; morte de familiar; presenciar dificuldades de relacionamento dos pais; nascimento de irmão e mudança de emprego dos pais (VECTORE; ZUMSTEIN, 2010).

McFarlane et al. (2005) descobriram por meio de exames da atividade elétrica cerebral a possível relação entre o estresse na infância com adversidades na vida adulta. Essas avaliações são difíceis de serem executadas, pela falta de profissionais, falta de equipamentos e à dificuldade de aceitação das mesmas para tais procedimentos. Outros fatores que dificultam o diagnóstico de quadros de estresse em crianças é a dificuldade das mesmas em descrever seus sentimentos e também pelo fato do estresse poder ser confundido com outras patologias (LIPP, 2000).

O estresse infantil, então, pode aparecer em qualquer idade. Em crianças, esse ambiente desagradável pode ser reflexo de problemas com a escola, em casa, com amigos ou com os próprios pais: "qualquer mudança na vida de uma criança pode estressá-la" (CROZERA, [s.d.], p.1).

Problemas familiares, ausência de um dos pais ou luto também podem criar situações de bastante estresse em uma criança. Mas uma das principais causas do estresse nas crianças, por incrível que possa parecer, são os pais. Enquanto para uma criança, a situação apresentada pode ser encarada como algo fácil para se lidar, para outra, a mesma situação, pode apresentar-se como algo "estressante". Dessa forma, os professores encontram, durante o ano letivo, alunos que apresentam comportamentos que chamam a atenção pelo fato de, ou não ser o habitual da criança, ou estar fora de uma realidade normalmente encontrada em crianças da mesma idade. Neste contexto, uma realidade que vem chamando a atenção é a questão do estresse infantil.

Neste sentido, Bignoto (2005) chama a atenção para a relação entre estresse infantil e estresse no adulto. A presença de pessoas estressadas em torno da criança deve ser considerada, pois um indivíduo estressado pode apresentar irritação, hipersensibilidade, falta de paciência, intolerância e mal-estar físico, fatores que podem interferir na qualidade de suas interações com a criança (VECTORE; ZUMSTEIN, 2010).

Sendo assim, pais estressados costumam transferir as cobranças que recebem aos filhos. Na tentativa de tornar os filhos competitivos para o mercado de trabalho no futuro, eles tendem a sobrecarregar as crianças com compromissos, como aulas de Inglês, Espanhol, computação, música, natação e outros esportes. E assim a criança fica com pouco tempo para fazer uma das principais atividades de relaxamento a que tem 
acesso: brincar e compartilhar a presença dos pais. Estes devem sempre tentar eliminar os fatores estressores dos filhos. O estresse infantil pode acabar prejudicando o desempenho escolar, as relações familiares e sociais, trazendo até mesmo problemas de saúde. Crianças que acabam se comprometendo logo cedo com afazeres domésticos, acabam encontrando dificuldades na escola. Devem se preocupar com responsabilidades escolares, tendo a vida toda para se preocupar com a casa.

Desta forma, os pais devem estar atentos aos sinais de estresse das crianças. É necessária uma atenção redobrada dos pais em relação aos sintomas de estresse infantil. Caso a criança apresente alguns sintomas, é necessário saber se há algo errado. Os principais sintomas costumam ser: irritação, mesmo quando não há motivo aparente; isolamento, quando a criança deixa de conversar com os pais e amigos e quer sempre ficar sempre sozinha; mudanças genéricas no comportamento: por exemplo, a criança sempre gostou de ir à aula de Inglês, mas passa a fazer birra toda vez que chega perto do horário da aula; mudança nos hábitos alimentares, mostrando desinteresse pela comida, mesmo pelas que mais gosta; mudança nos hábitos de sono; problemas digestivos: acidez no estômago e reclamações de dor de barriga; ansiedade; agressividade; problemas no desempenho escolar, esportivo ou social.

Assim, pressões sociais ou de trabalho nos pais também costumam atrapalhar o desenvolvimento da criança. Nascimentos indesejados também costumam ser causa de problemas para os bebês, ao atrapalharem a vida e os planos dos pais. Nesses casos, o problema não está com a criança, mas com os adultos. "A solução é que eles procurem ajuda em uma terapia para que a criança não sofra com problemas dos pais" (CROZERA, [s.d.], p.3).

Antigamente, as crianças ficavam mais soltas na rua e descarregavam a tensão em brincadeiras que envolviam exercícios físicos, nos quais se exigiam menos resultados que nos esportes atuais. Hoje, brinca-se em apartamento ou playgrounds de condomínios. A prática esportiva, por sua vez, quase sempre envolve competição e avaliação de desempenho. Entre os idosos também houve dramático aumento nos casos de estresse. Antes, as famílias moravam em uma mesma casa, com marido, mulher, sogros e avós. Atualmente, é comum que os mais velhos morem sozinhos ou em asilos, mantendo pouco ou nenhum contato com os familiares.

As principais recomendações a um adulto estressado são esporte e lazer; deixar de lado um pouco o ambiente de trabalho e criar tempo livre para praticar atividades prazerosas. O que fazer, no entanto, com uma criança estressada? A mesma coisa. As 
crianças precisam ter tempo para estudar, descansar e, principalmente, brincar. "A brincadeira funciona, para a criança, como uma válvula de escape, um estabilizador para a vida" (CROZERA, [s.d.], p.2)

É importante que os pais dediquem parte de seu tempo, saindo da rotina, junto com seus filhos, fazendo caminhadas e passeios; esses momentos de prazer, relaxamento e descontração podem servir como recursos de demonstração de carinho, segurança e transmissão de aprendizado, fazendo com que um elo de confiança seja estabelecido entre pais e filhos.

Outra ação importante para evitar o estresse na criança é respeitar o ritmo natural dela. Os ritmos de aprendizagem, crescimento e desenvolvimento são diferentes e os pais precisam saber lidar com isso. Até mesmo entre irmãos há essas peculiaridades, que devem ser observadas e levadas em conta quando se cobra algo de uma criança. A escolha da escola para um filho é muito importante. O perfil da escola deve se adequar ao perfil da criança. "Uma escola com um perfil mais firme ou mais livre pode atrapalhar bastante" (CROZERA, [s.d.] p.2).

Neste contexto do estresse infantil, uma questão importante e bastante atual é a sobrecarga que as crianças têm de múltiplas atividades. Os pais querem que as crianças aprendam tudo ao mesmo tempo. Não podem deixá-la aprender inglês depois, tem que ser agora, com cinco anos, por exemplo. Não sobra tempo para brincar. O que se deduz é que a vida moderna está causando um impacto grande na vida das pessoas.

A melhor forma de evitar o estresse é descobrir que está prejudicando a criança, não se tratando de um único fator, mas vários. Os pais devem procurar participar do dia-a-dia da criança e se sensibilizar melhor da presença do estresse, procurando as causas e eliminando-as. Muitas vezes, a ajuda de um psicólogo é necessária para ajudar a lidar com o problema. Pais alcoólatras, drogados ou até mesmo aqueles que falam alto, em tom agressivo, causam estresse nas crianças, além de provocarem danos psicológicos graves quando elas se tornarem adultas (Crozera, [s.d.]).

\section{Respostas psicobiológicas de estresse em crianças}

Por razões práticas e éticas há uma bibliografia escassa sobre as respostas de estresse em crianças. A exploração das respostas de catecolaminas e de cortisol em crianças sadias submetidas a estresse foi estudada por Johanson e Lundberg (GONZÁLEZ, 2001) em uma série de experimentos cuidadosos. 
O autor estudou os níveis de adrenalina em crianças de 03 anos de idade enquanto estavam nas suas casas em condições de relaxamento e quando estavam com um de seus pais em um hospital para fazer um exame médico de rotina. A expressão de adrenalina era marcadamente diferente em ambas as situações. No hospital, o nível médio de adrenalina era quase o dobro que na casa. Este resultado sugere que, nas condições hospitalares, as medidas "basais" de adrenalina não refletem necessariamente o nível basal real.

Nesse mesmo estudo no hospital as crianças foram separadas dos pais para fazerem uma avaliação psicológica. Aproximadamente a metade delas mostrou sinais de ansiedade e foi necessário que as mesmas fossem acompanhadas por um de seus pais. Aquelas crianças que expressaram níveis mais altos de ansiedade de separação mostraram também níveis mais elevados de catecolaminas (qualquer um dos hormônios derivados do catecol, sintetizados pelas glândulas suprarrenais e pelo sistema nervoso, que atuam como reguladores do metabolismo e como transmissores, tais como, a adrenalina, a noradrenalina e a dopamina) e de cortisol (hormônio produzido pelas glândulas suprarrenais, que estão localizadas acima dos rins) (GONZALEZ, 2001).

Outro estudo explorava a excreção de catecolaminas em crianças de 03 a 06 anos de idade durante atividades normais de brincadeiras em creches. As atividades muito estimulantes de jogos produziam uma excreção de adrenalina 50\% mais alta que na casa, enquanto que a noradrenalina não se elevava significativamente. Dado que a adrenalina é mais sensitiva à atividade mental do que a atividade física, os dados sugerem que, na creche, pela interação com outras crianças, as mesmas poderiam estar mais estimuladas mentalmente, e não, necessariamente, fisicamente mais ativas.

Em uma série de experimentos cuidadosos, Lundberg estudou em que medida os fatores psicológicos e psicossociais, além dos biológicos e genéticos, podem estar presentes desde a infância nestas variáveis moduladoras da resposta de estresse. Em crianças de creches, os níveis de excreção de cortisol e de catecolaminas, foram maiores nos meninos do que nas meninas. Aqueles meninos foram submetidos a situações de desafios emocionais (perseguir e agarrar a outras crianças) e desafio físico (correr o mais rapidamente possível). Os resultados foram consistentes com os encontros em adultos, já que a diferença do resto das crianças participantes apresentou um incremento maior na pressão sanguínea sistólica. $\mathrm{O}$ conjunto de resultados sugere a necessidade de estudar, desde sua gênese, todo um conjunto de variáveis psicobiológicas de estresse, que geralmente só se conhecem na idade adulta. Alguns dos resultados obtidos sobre o 
impacto do estresse nas crianças são os transtornos endócrinos como a diabetes mellitus e o hipertireoidismo. A resposta metabólica do estresse é a utilização de energia para seu uso emergente, que podem ser não armazenando substratos energéticos que estão na circulação, e pondo em circulação a energia previamente armazenada na forma de substratos. A primeira tarefa se realiza inibindo a realização de insulina. A colocação de energia na circulação se faz na base de glicorticóides, de catecolaminas e de glucagon que, além de inibir a liberação de insulina, mobilizam o glicogênio hepático, precursor de glicose (GONZALEZ, 2001).

A informação do efeito do estresse no metabolismo dos carboidratos e lipídeos, no particular na diabetes Mellitus, baseia-se em observação de pacientes com a doença, que diante de situações tensionais, sofrem metabolicamente. A diabetes Mellitus é uma doença autoimune que, na produção de insulina por células pancreáticas, se interrompe e o metabolismo dos carboidratos altera-se. Essa doença endócrina tem ajudado nos estudos sobre o estresse. Os métodos mais recentes de determinação de hormônios tireóideos dizem que sob o estresse existem leves incrementos destes hormônios, assim como mudanças no metabolismo. Desde 1978 existem várias equipes realizando pesquisas com o objetivo de conhecer o efeito do estresse na função tireóidea e sua repercussão na patogenia das doenças tireóideas mais frequentes, especialmente no bócio tóxico difuso ou no hipertireoidismo (GONZALEZ, 2001).

Quanto à relação entre estresse e escola, estudos em nosso país, realizados por Tanganelli e Lipp (1998) em 158 alunos de $1^{\text {a }}$ a $4^{\text {a }}$ série, com e sem dificuldades escolares, utilizando o Inventário de Sintomas de Stress Infantil (ISSI), constataram alta frequência de sintomas de stress, em particular entre os alunos mais fracos, com maior frequência entre as meninas, predominando os sintomas cognitivos (ficar preocupado com coisas ruins que podem acontecer, ter medo, vontade de chorar). Os alunos classificados como fracos mostraram ter dificuldade para prestar atenção e sentiam-se tristes. Os sintomas somáticos de stress mais comuns foram: mãos suadas, dor de barriga, não conseguir ficar parado e quieto num lugar por muito tempo e coração acelerado. Segundo Lipp, et al (1991), o estresse infantil ainda é demonstrado no nível físico por sintomas como dor de cabeça, náuseas, tique nervoso, ranger de dentes, e enurese noturna; e no nível psicológico por agressividade e pesadelos.

Relacionado ao estresse está a ansiedade. Segundo Rutter (1989), os eventos estressantes e o baixo status social estão relacionados à ansiedade, variável pouco estudada em nível epidemiológico. Multifatores estão associados à propensão à 
ansiedade, incluindo-se uma dimensão cognitivo-social e outra ligada ao contexto biológico (tensão nervosa e estresse), segundo dados da literatura resumidos por Nascimento (2001). Essa autora, enfatizando a dimensão interpessoal da ansiedade, mostrou haver relações entre o nível de ansiedade de alunos da $4^{\mathrm{a}}$ e da $8^{\mathrm{a}}$ série, medido pelo Inventário de Ansiedade Traço-Estado para Crianças (IDATE-C), e o nível de ansiedade de seus pais (IDATE).

Com essa pesquisa, pretende-se fazer uma análise sobre o estresse infantil e especificamente o estresse infantil na escola. Cada um está em um momento da vida. Aparentemente, o sofrimento é maior para a criança estressada que é muito mal compreendida e, muitas vezes, não vê legitimado aquele sofrimento. Por isso, acaba sendo tratada de forma pejorativa e costuma ser criticada. No momento de formação isso é muito importante, porque a autoestima está se desenvolvendo e a autoimagem se formando. E uma criança estressada e mal compreendida pode ter problemas de aprendizagem, desenvolver uma imagem de que não é capaz, e isso é seríssimo. Já na adolescência é uma fase de muitas mudanças e com tantos estressores, que é preciso ajudá-los a criar estratégias para lidar com o estresse, porque é uma idade muito decisiva para o futuro. Desta forma, é necessário aprofundar o conhecimento sobre maneiras para o professor garantir o sucesso dos alunos, o que contribuirá para prevenir o estresse escolar.

$\mathrm{Na}$ verdade, tanto pais como professores podem ser exigentes como uma característica de personalidade, mesmo sem estar estressados. No entanto, sendo exigente em um nível além da condição daquela criança, isso será, sem dúvida, um agente estressor. É válido lembrar também, que cada criança reage de acordo com sua personalidade; muitas vezes, os pais são exigentes e um filho não se estressa enquanto o outro se estressa demais, porque cada um vai ter o seu ritmo, o seu potencial. Os pais e professores, geralmente, educam da mesma forma suas crianças e adolescentes. No entanto, uma ou outra criança pode não conseguir atender a esse ritmo, o que gera queda de autoestima, fazendo com que a criança se sinta rejeitada, diminuída, e isso tudo pode ser um fator estressantes muito prejudicial ao desenvolvimento afetivo, identitário e social do aluno.

\section{Considerações finais}


O presente artigo objetivou caracterizar o surgimento do estresse e o impacto deste no processo de desenvolvimento, norteando educadores e pais a como identificar e trabalhar com este aspecto, uma vez que o estresse, quando se torna negativo, interfere diretamente no desenvolvimento integral do sujeito. O estresse é a adaptação da pessoa ocasionando uma reação física e emocional espontânea, que poderá tornar-se crônico. Existem dois tipos de estresse: o negativo (distresse), causado pelas frustrações e problemas diários, e o positivo (eustresse), causado por situações estimulantes (compra da casa própria, promoção no trabalho). As respostas são idênticas, aumento da pressão arterial, aceleração cardíaca, contração muscular, respiração rápida, podendo causa reações diferentes em cada indivíduo. A percepção da realidade é decisiva para o estresse tornar-se positivo ou negativo.

No mundo moderno a reorganização das relações de trabalho e das relações interpessoais acaba por criar um ambiente propício ao desenvolvimento de estresse. Todavia, tal mal é costumeiramente associado somente à adultos. Se o estresse afeta as famílias, implica consequentemente de forma direta na qualidade de vida das crianças também, o que somado a alta carga de afazeres que cada vez mais se imputam aos pequenos, podem gerar quadros de estresse infantil, que implicará decisivamente no desenvolvimento do infanto.

A escola deverá favorecer a contínua reconstrução das experiências inteligentes, mediante a aquisição de conhecimentos, a formação de atitudes e o desenvolvimento de habilidades que contribuam para a formação integral da personalidade da criança, lembrando que cada ser humano é produto único de experiências que, a partir do início da vida, começam a tomar forma, aumentando em complexidade, e no decorrer das quais as características pessoais vão sendo marcadas. Entre irmãos e entre membros de uma mesma classe social encontram-se diferenças acentuadas na forma de ser, de enfrentar os desafios e dificuldades que ocorrem durante o período de crescimento, evolução e aprendizado.

Podemos observar que na maioria das vezes o estresse vem de casa, da família e do convívio com familiares e isso reflete na escola, o professor tem que saber lidar com isso para poder amenizar os impactos. Dessa forma, este estudo poderá auxiliar a embasar, futuramente, a aplicação desses conceitos em estudos de campo, os quais certamente comprovarão os amplos benefícios do uso de estratégias para combater e/ou evitar o estresse. 


\section{REFERÊNCIAS}

ARANTES, Maria Auxiliadora de Almeida Cunha; VIEIRA, Mario Jose Femenias. Estresse: a sombra, o bom e o mau estresse. São Paulo: Casa do Psicólogo, 2002.

BIGNOTTO, Márcia Maria. O papel dos pais na prevenção do stress infantil. In: LIPP, M. E. N. Crianças estressadas: causas, sintomas e soluções. 4 ed. Campinas, SP:

Papirus, 2005.

BRONFENBRENNER, Urie. A ecologia do desenvolvimento humano: Experimentos naturais e planejados. (M.A.V. Veronese, Trad.), Porto alegre: artes Médicas. (Original publicado em 1979), 1996.

CROZERA, Luiz Carlos. Estresse infantil. [s.d.]. Disponível em:

$<$ http://www.institutohipnologia.com.br/index.php?option=com_content\&view=article \&id=16:estresse-infantil\&catid=6:gerais\&Itemid=18>. Acesso em: 10 abril de 2017.

DELL'AGLIO, Débora Dalbosco.; HUTZ, Cláudio Simon. Estratégias de coping e estilo atribucional de crianças em eventos estressantes. Estudos de Psicologia, v. 7, p. $5-13,2002$.

EFRAIM, Carlos Costa et al. Percepções sobre o estresse entre professores universitários. Revista Rene. Fortaleza: v. 6, n.3, p. 39-47, set/dez. 2005.

GONZÁLEZ, Miguel Angel Álvarez. Stress: Temas de Psiconeuroendocrinologia. 2. ed. São Paulo: Robe Editorial, 2001.

HORTA, Ligia Ribeiro. Estresse infantil: Um estudo exploratório com pré-escolares. 2007. 145 p. Monografia (Pós-Graduação em Psicologia -Mestrado) - Universidade Federal de Uberlândia, Uberlândia, 2007.

JOHANSON, Martin.; LUNDBERG, Heléne. Network strategies for regional growth. New York: Palgrave Macmillan, 2011.

LIPP, Marilda Novaes. Crianças estressadas: causas, sintomas e soluções. São Paulo: Papirus, 2000.

LIPP, Marilda Novaes et al. Como enfrentar o stress infantil. São Paulo: Ed. Ícone, 1991.

LIPP, Marilda Novaes. Como enfrentar o estresse. São Paulo: Ícone Editora, 1990.

LUNDBERG, Ulrika et. al. Blood lipids as related to cardiovascular and Neuroendocrine functions under different conditions in healthy males and females: Pharmacol. Biochem. Behav, v. 33, p. 381, 1989.

MARGIS, Regina et al. Relação entre estressores, estresse e ansiedade. Rio Grande do Sul: abril, 2003. 
MARTURANO, Edna Maria. Tensões Cotidianas na transição da primeira série: Um enfoque de desenvolvimento. Psicologia em estudo. Maringá, v. 13, n. 1, p. 79-87, jan./mar., 2008

MOMBELLI, Mônica Augusto et al. Estrutura e suporte familiar como fatores de risco de stress infantil. Estudos de Psicologia, Campinas, v. 28, n. 3, p. 327- 335, julho/setembro, 2011.

RUTTER, Michael. Continuidades e descontinuidades entre gerações em sérias dificuldades parentais. Nova York: Cambridge University Pres, 1989.

SAMEROFF, Arnold Joshua. Human Development: Transactional models in early social relations, 1975.

SLEE, Phillip.; MURRAY-HARVEY, Rosalind.; WARD, Harry. Stressed Out \& Growing Up. Every Child: School of Education, v. 2, n. 4, 1996.

\section{Como referenciar este artigo}

PACÍFICO, Marsiel.; FACCHIN, Marcele Martins Provinciatti.; CORRÊA SANTOS, Fabiana de Fatima Ferreira. Crianças também se estressam? A influência do estresse no desenvolvimento infantil. Temas em Educ. e Saúde, Araraquara, v.13, n.1, p. 107-123, jan./jun. 2017. DOI <https://doi.org/10.26673/rtes.v13.n1.jan-jun2017.8.10218>. ISSN: 1517-7947.

Submetido em: 03/08/2017

Aprovado em: 30/09/2017 